\title{
Smart Cities and Innovation Clusters
}

\author{
Jean-Alain Héraud1,2, Emmanuel Muller 1,3,4 \\ ${ }^{1}$ BETA, Université de Strasbourg, Strasbourg, France \\ ${ }^{2}$ CNRS, Strasbourg, France \\ ${ }^{3}$ University of Applied Sciences, Kehl, Germany \\ ${ }^{4}$ Fraunhofer ISI, Karlsruhe, Germany \\ Email: muller@hs-kehl.de
}

How to cite this paper: Héraud, J.-A., \& Muller, E. (2022). Smart Cities and Innovation Clusters. Open Journal of Business and Management, 10, 387-401. https://doi.org/10.4236/ojbm.2022.101023

Received: November 15, 2021

Accepted: January 23, 2022

Published: January 26, 2022

Copyright ( 2022 by author(s) and Scientific Research Publishing Inc. This work is licensed under the Creative Commons Attribution International License (CC BY 4.0).

http://creativecommons.org/licenses/by/4.0/

\section{(c) (i) Open Access}

\begin{abstract}
The issue considered here is the interplay between smart cities (SC) and innovation clusters. Both concepts have been considered independently in the recent decades-in theoretical and applied literature-but little attention has been paid so far to the links between them. The research approach of the paper is a combination of literature review and observation of case studies in Europe. Our approach is strongly influenced by the philosophy of foresight and technology assessment, having in mind the construction of a desired consensual future, not a deterministic technological vision. With this presentation, we particularly aim at the municipal policymakers or managers, and at people involved in technological clusters, research centers, fab labs, living labs, etc.
\end{abstract}

\section{Keywords}

Smart Cities, Innovation Clusters, Living Labs, Participative Democracy, Technology Assessment

\section{Introduction}

The aim of this paper is to provide some insights into the interplay between smart cities (SC) and innovation clusters. In recent years, SC and clusters have separately been the object of a considerable number of analyses, academic articles and policy reports. Nevertheless, very little attention has so far been paid to the links between them. Consequently, the ideas developed in the following pages constitute an attempt to shed light on the conceptual and empirical links between the two notions. We also intend to precise our definition and approach of SC in order to escape the reductionist technological bias. It would be intellectually misleading and politically dangerous to present the issue in the following 
way: the SC is basically an application of the new numerical technologies (TIC) to urban design and management; the ideal SC must organize or attract clusters specialized in ICT applications for helping the development of an interactive intelligent system. We consider it essential to extend the definition of "smart" to other dimensions of the ideal city: sustainability, inclusiveness, equality, social innovations. Therefore, the interactive intelligent system is not limited to technical artifacts, but before all must be a collective human intelligence. The SC is at the service of the citizens, not the opposite. To avoid organizational drifts and political abuses, the city has to deal first with human connectivity, social inclusion, and participative democracy.

From the viewpoint of system dynamics and evolutionary economics, it is also important to underline the spontaneous self-organizing mechanisms that lead to technological, organizational and societal innovation. Long run evolutions cannot be planned, just piloted (Héraud, Kerr, \& Berger-Helmchen, 2019). SC is a form of organizational innovation, but it is also a geographical context for specific innovations, for the development of entrepreneurship, for the test of innovative goods and services. The city can act as a lead user for instance, or offer a fertile context for entrepreneurial activities. Piloting innovation is at the core of the notion of SC, knowing that the function of "pilot" is not that of a planner. The pilot plays with opportunities, adapts the policy to the complex adaptive system he/she has in charge, respects and facilitates its permanent self-organizing creativity. The existence of innovative clusters within the perimeter of the SC is therefore quite natural.

As for the above-mentioned lack of literature linking SC and innovative clusters, there are some exceptions. At least, innovation and entrepreneurship are linked to SC in contributions like Richter et al. (2015): "[a] Smart City is an agglomerated area affected by a high concentration of learning, entrepreneurship and innovation as a result of creative citizens and institutions as well as the implementation of a digital infrastructure" (op. cit. p 222). Hajduk (2016) explains that the specific character of an SC consists in creating and consolidating knowledge and innovation. This is the reason why the implementation of smart initiatives increases a city's social and economic attractiveness and competitiveness supported by its technological infrastructure. Kraus et al. (2015: pp. 603-604) use the term "cluster": "[an] important aspect for smart cities is the geographical proximity of like-minded persons, also called a cluster or 'magnet for creative people and workers' (...) Competition can result in innovations delivered at a faster pace, and smart cities are getting even smarter, due to a cluster effect".

We start then with such questions: How can clusters support the development of SC? How can SC foster clusters? What are the enablers for and obstacles to the convergence between them? Empirical observations of national, regional and local examples are provided in this article illustrating the possible convergence. Interestingly and according to the knowledge of the authors, even if 1) there is a very broad literature on clusters worldwide and 2) several analyses can be found 
on smart cities, no investigation has been devoted so far to the possible interrelations between the two concepts.

\section{Several Definitions and Approaches of the Smart City}

In many articles on SC the focus is on the technological and organizational conditions for their emergence. In such a vision the new digital applications are the main drivers of an evolution towards a more efficient management of urban systems. The first metropolitan experiences in various parts of the world have indeed started with the help of private partners specialized in IT services and are understood as an application of artificial intelligence (AI). A typical example is the Toronto experience with Google (Alphabet) in the Quayside area: Sidewalk side. IBM launched in 2008 its program called Breakthrough of smart city in China. Cisco succeeded to test and develop its application Kinetic in many cities-not only capital towns like Paris, but also medium-sized metropolitan agglomerations: Hamburg in Germany, Adelaide in Australia, Kansas City in the US, etc. The technological version of SC is tested and advertised in a whole variety of contexts, from Los Angeles in California to Faro in Portugal.

Our argument in this article concerning the notion of SC is that municipalities must be very careful in choosing their model and the main partners for implementing it. The issue is about technological choices, but even more about the relative importance given to the technological aspects as compared to organizational, political and societal aspects. We start from the philosophical (i.e. ethical, political) viewpoint that the core definition of smart city should be based on a principle of distributed intelligence (see Kuhlmann et al., 1999) and therefore linked to the model of participative democracy. Technology is unfortunately compatible with both advanced democracy and backward dictatorship. Since technological choices are never neutral, it is important to think simultaneously technological and societal dimensions of the SC.

\subsection{Functions and Critical Factors of Smart Cities}

The term smart city emerged progressively in the 1990s. The concept has become increasingly popular in scientific literature and international policies. According to Albino et al. (2015), the California Institute for Smart Communities was among the first to focus on how communities could become smart and how a city could be designed to implement information technologies. Over the past twenty years, the SC concept has had many definitions, but globally they are places where information technology is combined with infrastructure, architecture, everyday objects and our bodies to address social, economic and environmental problems.

Considering the numerous definitions of SC in the literature, Chourabi et al. (2012) pinpoint the following functions. It is a city that can:

- connect the physical infrastructure and the IT infrastructure with the business infrastructure to leverage the collective intelligence of the city; 
- strive to make itself "smarter" (more efficient, sustainable, equitable, and liveable);

- combine different technologies with (urban) planning efforts and organizational aspects in order to design, dematerialize and speed up administrative processes;

- perform well in a forward-looking way in its economy, people, governance, mobility and environment, built on a smart combination of its endowments and the activities of its citizens;

- monitor and integrate the conditions of all of its critical infrastructures, including roads, bridges, tunnels, railways, underground railways, airports, seaports, communications, water, power, even major buildings, and can therefore better optimize its resources;

- plan its maintenance activities and even monitor security aspects in order to maximize its services to citizens.

It is clear that the global rise of cities and megacities generates new kinds of problems: human health concerns, difficulties in water and waste management, air pollution, lack of social inclusion, traffic congestion, etc. Addressing these challenges linked to societal and environmental sustainability can be enabled by SC solutions: integrated transport offering inclusive connectivity; secure and clean energy; environment and resource efficiency; health, safety and security, etc. At the same time, it is necessary to acknowledge that science and technology can only account for a part of the challenges listed above.

Against this background, Chourabi et al. (2012) identify eight critical factors of SC initiatives: they must 1) link technology, organization and policy in a sensible way and 2) link, as a second tier of achievement, the domains of built infrastructure, economy, natural environment, people community and governance structures. Many aspects of urban development cannot be fully addressed through physical communication devices and digital treatment. Typically the role of communities and the issue of governance need a very specific approach, where ICT can just be considered as an instrumental help and certainly not as the main driver of evolution. Caragliu et al. (2009) consider that urban performance-not to speak of ethical aspects concerning social inclusion and long run sustainability - strongly depends on human and social capital.

ICT-based development projects can change the urban landscape of a city and offer interesting potential opportunities, improving the citizens' quality of life, but they can also increase inequalities, for instance because of the digital divide. Furthermore, implementing centrally controlled ICT tools means increased top-down regulation, which is the opposite of creativity and participative democracy.

\subsection{The Risk of Technological Bias}

The technological implementation of information and knowledge networks will increasingly be IA-based. It is supposed to be a progress in territorial intelli- 
gence, but it is not neutral from a philosophical viewpoint. It is an individualistic and centralized approach of the urban organization. The communication networks are very pervasive, but the system cannot be characterized as "distributed intelligence" (in the sense of Kuhlmann et al., 1999), since the global design follows a top down model. Like in mainstream economic theory, the paradigmatic assumption is methodological individualism: the user (citizen, firm...) is given a specific rationality and supposed to respond to the bits of information, prices and specific incentives, by standard reactions. The good citizen is individualistic-only interested in his/her own well-being-, but never cheating with the rules. The issue here is that a large part of contemporary economics, following the seminal works on experimental economics like Thaler and Sunshine (2008), disagree on such assumptions, and propose alternative incentive schemes in terms of nudges. More generally the issue is about the conception of well-being.

The numerical a priori of the basic SC conception implies that the future of cities goes through IT, in the sense that the administration as well as the citizens and the firms located in such spaces are increasingly involved in the numerical practices and behave in the "right way" - the latter normative attitude being, to a large extent implicitly, defined by the organization. This SC project looks therefore like a collective learning process: a multi-level and multi-actor permanent experience. The idea is almost pedagogical: how to make real actors act like "rational" agents.

In this full technological vision-let's call it technological utopia-of SC, information is exchanged in real time by users of the various networks (for mobility, energy, etc.) along centrally organized schemes. Individuals do communicate horizontally among themselves as well as vertically with the system, but mostly in a non-deliberate way, for instance through internet of things. Let's underline the fact that such a global system can maybe reach optimality, but only in a static way. There is no creativity outside the top management, the people who design and run the organization. And in case of a strong input of AI, it is not even granted that somebody has full control of the SC and can apply a clear deliberate strategy. The future has no self-organized rationale in a human sense. Citizen's creativity is very limited.

Many critiques have warned against the potential danger of designing SC as a technological utopia, considering it looks more like a dystopia. Among the recent publications, see Eveno (2018), Vidalenc (2019) and David \& Sauviat (2019). A smart city is, before all, a city where the population is happy to live in. It means that "happiness" should be the central indicator of the project. But wellbeing is a better concept than happiness if we consider it in the sense of Sen (2009): giving people the possibility to realize themselves.

In the wake of participative democracy, increasing interest is devoted to enquiries about the wellbeing of the inhabitants. It was for instance the case of the Strasbourg urban area (CD-EMS, 2018). Such enquiries certainly contribute to the development of the SC. The basic idea is to understand which factors 
strongly impact (positively or negatively) the individual and collective wellbeing. Is it mainly economic opportunities, quality of life, environmental issues, health, cultural supply, security, equality and inclusion...? What is the ranking of importance/urgency in any additional supply of services or amenities among all these topics? What is presently growing in relative importance? Where are the main contradictions (demographic and economic growth versus quality of life; touristic attractiveness versus authenticity; urban sprawling versus housing densification; security and social control versus individual liberty; etc.)? Wellbeing should be the real issue of urban policy, and the SC has to reflect this basic principle. No top down governance should impose the collective aims. The new technologies give a possibility to better integrate the feelings of the population, constructing common knowledge about possible and desirable futures (futuribles) - as far as the system is not a priori configured on the basis of technocratic assumptions.

Consequently, we propose the following extended definition of smart cities initiatives: a smart city initiative corresponds to a set of policy actions and technical realizations, which aim at increasing citizens' well-being in using mainly ICT facilities and knowledge-intensive resources.

\section{A Convergence between Smart Cities and Innovation Clusters?}

As indicated in the introduction, smart cities appear to be vectors of innovations-in processes, product or services. Innovative activities that are specific to a territory relate to the concept of cluster. Let's first remind the definition of such creative ecosystems.

Following the seminal works by Michael Porter (see Porter, 1998), different definitions of clusters can be found in the literature. They can be defined as groups of specialized enterprises (often SMEs) and other related supporting actors that cooperate in a particular location. Clusters are commonly concentrated on one or more sectors within a specific region. They also emphasize networking and cooperation between companies and institutions, internal and external to the region. In this respect, clusters can be seen as groups of firms, related economic actors, and institutions that are located near each other and have reached a sufficient scale to develop specialized expertise, services, resources, suppliers and skills. Historically, the USA was the first country to use the cluster concept for economic development. The most striking example of its application was Silicon Valley, which unites more than 7000 representative offices of highly technologically developed enterprises and firms, 1.35 million jobs within a radius of $160 \mathrm{~km}$ and 2.5 million residents. Implicitly, clusters are due to their nature always based on knowledge spillovers. According to the literature and to empirical observations, clusters are commonly highly innovative. A cluster "rests on innovation" (Porter, 2000: p. 256). Therefore one can also speak of "innovation cluster" when innovativeness appears as the main driver of a cluster competitiveness. 


\subsection{Smart Cities and Innovation}

The core technical challenge for an SC is to build the foundation for a favourable environment with information sharing, collaboration and interoperability for all inhabitants anywhere in the city, meaning that ICT is an enabler of urban welfare (Kraus et al., 2015). Nam and Pardo (2011: pp. 286-287) highlight the fact that mobile, virtual, and ubiquitous technologies are not only constitutive elements of SC, but that " $t]$ hose technologies offer benefits to city dwellers in mobile lifestyle. Smart city application evolves from smart places to networked inhabitants. While the wireless infrastructure is a key element of digital city infrastructure, it is only a first step. A set of technological requisites for smart city comprises network equipment (fibre optic channels and Wi-Fi networks), public access points (wireless hotpots, kiosks), and service oriented information systems. A ubiquitous/pervasive computing infrastructure is a key technological component in the build out of a digital city".

The "digital city" model of SC is therefore a typical case where innovative clusters are part of the story. Nevertheless, the wording "urban welfare" indicates we are here in a classical economic and technological vision. Wellbeing-individual and collective accomplishments-is not really taken into consideration.

In the introduction, we asked the question: how can clusters support the development of SC? In a digital city vision, the answer is evident if the clusters are strongly linked to ICT applications. Nevertheless it would be interesting to consider other cases where ecosystems of innovative firms contribute to the collective creativity of the city by formulating new ideas which are not strictly related to ICT (even if digital technologies are nowadays present in every sort of innovation, they are not in every case the main trigger). What about societal innovations, exploitation of traditional local knowhow or specific natural resources, etc.? In such domains clusters will help to ensure sustainability and inclusiveness of the SC. Maybe better than certain high tech specialties that could suffer from obsolescence or sectoral crisis in the future.

The second question was, conversely, the SC capacity to boost or attract clusters. Kraus et al. (2015) give many evidences in this field. Such cities tend in a natural way to favor the emergence of clusters through reinforced agglomeration effects. Among the factors that directly impact innovation and entrepreneurship let's mention:

- The high availability and quality of ICT infrastructure and usage, as well as the availability of databases;

- The demand of urban residents for social inclusion in public services that generates strong business opportunities;

- The positive image of SC, which is a factor of attractiveness for highly skilled human resources and a marketing instrument for entrepreneurs.

Again, in an extended approach of the SC, we would consider other factors of attractiveness like quality of life, cultural heritage, natural assets, and many forms of urban amenities. 
The last question raised in the introduction concerns the context in which SC develops: what are the main positive and negative contextual elements for the convergence SC/clusters? We answer it the next paragraph.

\subsection{Enablers and Obstacles}

The question of the convergence between smart cities and clusters is studied in Angelidou (2015). For the author, "smart technologies" provide local functional capabilities not only through physical instrumentation, but also though people and activities. "Integrated smart city strategies" aim to connect the physical space of cities with the economic and social sphere. Nevertheless the success of such strategies depends on different conditions, and contradictions may arise in SC strategies. In the literature we can find examples of positive and negative factors (enablers/obstacles). Let's start with the enablers.

- Urban planning is the first crucial factor for the development of smart cities and their propensity to foster the emergence of clusters and for them to flourish. Effective urban planning in this context requires intellectual resources and proper institutions, in particular, to support the expansion of the infrastructures developed previously. Hajduk (2016) stresses some urban facilities that must be incorporated in the SC plans in any case: technology parks, R\&D companies, business incubators, technology transfer centres and industrial complexes

- According to Kraus et al. (2015), public-private partnerships are very useful. Examples of public-private partnerships making the link between SC and cluster development can be found for instance in the development of science parks, digitisation hubs or fab labs by local authorities to attract more entrepreneurial individuals and organisations.

- Social sustainability and education are the third enabler which is crucial for the wellbeing of the inhabitants of SC, as well as for cluster development. In this respect, Angelidou (2015) recommends notably to pay attention to issues of accessibility for all and to avoid digital disparities as well as spatial polarization. Kumar (2017) suggests the development of economic clusters where micro-, small-, and medium-sized enterprises can meet, develop business blueprints and knowledge-based economy plans.

We want to add to this series of enablers the quality of the local context in terms of collective intelligence and social learning. Here we can use the concept proposed by Nam and Pardo (2011), the smart community. It is difficult to plan the development of such a local community, but for the cities who by chance have a part of their population capable of developing networked intelligence, nurturing continuous learning, being an SC is just a normal situation, whatever the technologies on which SC is to be built.

In terms of the obstacles, the most noteworthy challenges are the following:

- Investment capacities are a typical limitation (Kraus et al., 2015). At least at the beginning of the process of a city becoming "smart", limited financial re- 
sources of public authorities and higher operating costs may lead to a lack of investments. Here the size of the city plays an important role, because such projects are not only risky but also exhibit indivisibilities issues. If the development of SC and related clusters may constitute part of the solution in the long run, it is a real problem in the short or middle term.

- The second category of obstacles in the possible reluctance of citizens. As underlined previously, since SC are not only projects about technology and data, the social dimension must also be taken into consideration. In other words, a city's "smartness" depends crucially on citizens' participation in the projects. This includes also how to deal with vested interests (such as taxi drivers' opposition towards new integrated mobility solutions being offered at train stations and airports). Without appropriate communication and space for bottom-up participation, a pure technological top-down approach is likely to fail or at least to prove sub-optimal in terms of results.

- Finally, there are potential hindrances in privacy and security issues. Even in situations where citizens and companies display a strong interest and seem to be willing to support the process of their city becoming smart, issues of individual privacy and business secrecy appear as barriers. In a world where cyberattacks are becoming more and more frequent, SC-related clusters need to contribute to the constitution of protective walls. This is not one of the missions usually attributed to clusters and in the worst case scenario (i.e. cyberattacks organised by enemy countries or terrorist groups) there is a question as to whether SC networks potentially generate strategic weaknesses.

\section{Lessons Learnt from a Comparative Analysis of Smart City Cluster Initiatives}

An empirical investigation of the links between smart cities and clusters reveals the existence of several types of relationship at different geographical levels (local, regional, national and also European).

In this section, examples of smart cities initiatives will be investigated in order to illustrate the connections between SC and innovation cluster and to draw some lessons. Cluster initiatives can foster the development of SC development and even more frequently, SC can be cluster boosters. In this perspective, the initiatives analysed in this paper may indeed represent what Alaverdyan et al. (2018) have called Smart City Clusters. They define them by the notion of "co-operation of institutionalized actors through cluster initiatives".

\subsection{Some Examples}

At local level, the main initiatives identified show that the SC concept may be promoted by clusters as well as by Living Labs $(L L s)$, two distinct but complementary approaches which, although playing different roles in supporting the information value chain, can contribute to the smart upgrade of cities by advocating the importance of research and having innovation at their core (Cosgrave 
et al., 2017). Defined as a "system enabling people, users/consumers of services and product, to take active roles as contributors and co-creators in the research, development, and innovation process" (Arnkil et al., 2010), Living Labs facilitate university-industry-end-user relationships and contribute in developing and testing innovative urban solutions in a real-life context. As a result, like clusters, they foster relationships among stakeholders and thus may be considered complementary to traditional regional innovation policy (Almirall \& Warenham, 2008). This complementarity is also reflected in the different purposes of the two approaches: while Living Labs are more focused on the product development, clusters are generally more oriented towards market development.

Initiatives characterized by a strong link between SC and clusters can also be identified at regional and national levels. Differently from local examples, which appear to be more focused on specific products or types of market, regional and national initiatives generally have a broader scope. Their agenda mainly revolves around technological aspects of the SC concept, energy, transport, infrastructure and mobility being the most relevant fields of interest across clusters. However, smart governance and e-government, health, education and training, and cultural heritage also play a significant role in their cluster strategies.

At national level, the Smart City Lab Cluster in Estonia is one of the most successful examples of national cluster strategy focused on the development of SC, also in view of the high importance that Estonia attaches to this concept. Created first as a joint project between the City of Tartu and ICT companies, the cluster currently brings together businesses, citizens, public authorities, R\&D institutes and structures supporting innovation and its core goal is to help co-create, develop and export innovative and smart solutions, especially in the fields of transport, governance and infrastructures. Two similar examples, although with a different focus, can be mentioned: the Czech Smart City Cluster and the Cluster Smart City (ViP) in Latvia. They promote the SC concept by focusing more on the promotion of the SC technology market position of their cluster's members. Further examples of Living Labs created to promote the smart development of cities may be found for instance in Amsterdam $(A L L)$, Barcelona (22@Barcelona), Helsinki (FLL) (Bifulco et al., 2017; Alaverdyan et al., 2018).

Amongst the regional initiatives, the Andalucía Smart City cluster represents an example of an alliance of private companies, institutions from the energy, environment, transport, ICT and mobility sectors, cities and universities, aimed at the creation and development of sustainable, efficient and comfortable smart cities as well as of jobs and wealth in the urban business community. To achieve these goals, a key contribution comes from the sharing of research, development, innovation and know-how among its members and across different sectors, such as energy, environment, infrastructure, information and communication technologies and urban mobility. Similarly, also the Italian initiative in the Lombardy Region The Technologies for Smart Cities \& Communities promotes and fa- 
cilitates research in support of sustainable innovation in the field of smart cities and communities, bringing out the synergies between companies, research centres and universities. The ultimate aim of the cluster is to implement the most advanced technology solutions at an urban and metropolitan scale. This is to be achieved by establishing cooperation with the public administration in the following fields: renewable energy and energy efficiency, security and territorial monitoring, mobility, health, wellness, e-government and justice, education and training, cultural heritage and tourism.

At European level, the SC concept is to be found in cluster partnerships across several countries and different entities. The main clusters identified in this respect are the Smart Cities Mediterranean Cluster and the Smart City Tech. While the former consists of a close partnership between research centres, industry, innovative SMEs and civil society from 26 countries aimed at identifying a common approach in specific fields of SC strategies, the latter can be seen more as an inter-cluster partnership with the final aim of stimulating the cooperation between cities and smart system stakeholders, such as companies, policy makers, academia, investors and citizens.

\subsection{Lessons from the Selected Examples}

Our hypothesis of a natural connection between SC and innovation cluster seems confirmed. An existing cluster can be the main support of the SC development, but many existing SC can be seen as seedbeds for clusters. In a higher number of cases the second option is the more likely.

As for the living labs, the two ways of convergence do also exist. For instance, the Amsterdam Living Lab (ALL) was specifically created for the development of the Amsterdam smart city in 2009. Conversely, 22@Barcelona was firstly created to support business innovation, and only at a later stage it supported SC initiatives. Because they are nested within SC, living labs nurture two-way relationships, both contributing to and taking advantage of the dynamics of SC development. This is also true for clusters.

As we have already stressed, successful implementation of SC implies citizens' acceptance and inclusion, as citizens are the main reason for the existence of a city and its policies. Moreover, an SC is not the result of a top-down vision-or not mainly. Municipal investments are generally just a part of the operation, and it is difficult to create a whole system out of nothing. SC is a complex organic thing, a system of systems (Harrison \& Donnelly, 2011). It is an ecosystem of products, services, companies and citizens collaborating with the aim to foster innovation ideas within a city (Cosgrave et al., 2017). Nevertheless, activities to improve the interaction between cities and citizens, which are a crucial factor for SC development according to Wang (2015), Corrigan and Joyce (1997) and Nalbandian et al. (2013), seem not to be a prominent characteristic of most of the selected examples.

When focusing on the type of stakeholders involved, in fact, the identified 
Smart City Clusters are usually represented by science (universities, research centres, science supporting institutions, etc.), industry (enterprises) and government (including regional and local administrations). Beside the preponderant involvement of industry, science institutions are almost always included in the cluster organisations. For example the Cluster Smart City (ViP) in Latvia, involving only Latvian entrepreneurs and research organisations or SC technological firms, includes cluster partners and the related companies. Similarly, but to a lesser extent, the role of government and public administrations is particularly relevant.

Conversely, a less relevant connection may be detected in the activities improving the interaction between the city and its citizens: we observe a low level of involvement of the users/citizens sphere in the cluster organisations linked to SC, and this is a problem since city's smartness depends also on citizens' participation in the SC projects.

Overall evidence on the ground indeed shows that the Triple helix proposed in the 1990s by Etzkowitz and Leydesdorff (1995) is the main approach used for the development of clusters initiatives connected to SC. Examples of the complement in a fourth sphere (users/citizens) which is a characteristic of a Quadruple helix (Waart et al., 2016; Carayannis \& Campbell, 2009) can be found in the Smart Cities Mediterranean Cluster, the Smart City Cluster in Estonia and the Czech Smart City Cluster only. Likewise, on a smaller scale, Living Labs, which are based on the concept of "open innovation", also promote a Quadruple helix vision, by gathering researchers, firms, users, public partners and other stakeholders in an innovative environment.

\section{Conclusion}

In this attempt to think together smart cities and innovative clusters we arrived at a certain number of conclusions. First, it really makes sense to link the urban future and the knowledge and innovation economy. From this point of view, thinking the "smart city" is close to a foresight exercise anticipating technological developments and societal changes, preparing for the possible futures, adapting the urbanism and the physical and intellectual infrastructures for all the scenarios under consideration. Implementing numerical solutions is of course part of this project, but certainly not the only aspect to consider.

This approach corresponds to the idea of foresight as a strategic management tool. But foresight also means creating collectively a set of representations of the future. The French school of prospective has coined the word "futurible" to express the idea of "possible and desirable futures"-the latter being collectively constructed, not imposed by the hierarchy. Therefore, the smart city has to consider also social and political interactions, and procedures for achieving the participation of the inhabitants in the preparation of the future.

Returning to the cluster issue, another important idea is that such innovative ecosystems definitely help to become smarter-not only because they bring new 
technological solutions, but because they are a way to organize collective creation among a certain set of actors within the urban system. Furthermore, in order to fully contribute to the "smart city" objective, they must be interrelated. From this point of view, the smart city is a meta-cluster (a cluster of clusters).

The preceding view should be still improved, because it looks a little too "technology-oriented". It corresponds to the concept of Triple Helix (linking firms, research and education, and local governance structures), but we are looking for a Quadruple Helix including the users and the citizens.

The fourth dimension raises specific questions like the right balance of vested interests, or the inclusiveness of governance. We have to check if the numerical and technological smart city is also a city where the inhabitants are happy to live. A step further in the questioning is to define happiness - or more precisely well-being, because individual and short-term happiness cannot (or must not) be the aim of the urban policy. Being "happy" to live in town means to benefit from convenient and efficient services, but not only. The real aim of the smart policy should be the full-fledged satisfaction of the citizen: being part of the city, an actor of the system in the long run. In this sense, the concept of smart city must be related to the idea of sustainable collective well-being.

\section{Conflicts of Interest}

The authors declare no conflicts of interest regarding the publication of this paper.

\section{References}

Alaverdyan, D., Kučera, F., \& Horák, M. (2018). Implementation of the Smart City Concept in the EU: Importance of Cluster Initiatives and Best Practice Cases. International Journal of Entrepreneurial Knowledge, 6, 30-51. https://doi.org/10.37335/ijek.v6i1.67

Albino, V., Berardi, U., \& Dangelico, R. M. (2015). Smart Cities: Definitions, Dimensions, Performance, and Initiatives. Journal of Urban Technology, 2, 3-21. https://doi.org/10.1080/10630732.2014.942092

Almirall, E., \& Wareham, J. (2008). Living Labs and Open Innovation: Roles and Applicability. The Electronic Journal for Virtual Organizations and Networks, 10, 21-46.

Angelidou, M. (2015). Smart Cities: A Conjuncture of Four Forces. Cities, 47, 95-106. https://doi.org/10.1016/j.cities.2015.05.004

Arnkil, R., Järvensivu, A., Koski, P., \& Piirainen, T. (2010). Exploring Quadruple Helix Outlining User-Oriented Innovation Models.

Bifulco, F., Tregua, M., \& Amitrano, C. C. (2017). Co-Governing Smart Cities through Living Labs: Top Evidences from EU. Transylvanian Review of Administrative Sciences, 13, 21-37. https://doi.org/10.24193/tras.2017.0002

Caragliu et al. (2009). Smart Cities in Europe. Journal of Urban Technology, 18, 45-59.

Carayannis, E. G., \& Campbell, D. F. (2009). Mode 3 and Quadruple Helix: Toward a 21st Century Fractal Innovation Ecosystem. International Journal of Technology Management, 46, 201-234. https://doi.org/10.1504/IJTM.2009.023374

CD-EMS (2018). Comment ça va? Résultats d'une enquête citoyenne sur le bien-être, 
Volume 1: Les déterminants principaux du bien-être, exprimés par les participants. Conseil de développement de l'Eurométropole de Strasbourg.

http://www.citoyensterritoires.fr/sites/cpl.asso.fr.temp/files/eurometropole contributio n sur le bien-etre.pdf

Chourabi, H., Nam, T., Walker, S., Gil-Garcia, J. R., Mellouli, S., Nahon, K., Pardo, T., \& Scholl, H. J. (2012). Understanding Smart Cities: An Integrative Framework. In 45th Hawaii International Conference on System Sciences (pp. 2289-2297). Springer. https://doi.org/10.1109/HICSS.2012.615

Corrigan, P., \& Joyce, P. (1997). Reconstructing Public Management. A New Responsibility for the Public and a Case Study of Local Government. International Journal of Public Sector Management, 10, 417-432. https://doi.org/10.1108/09513559710190799

Cosgrave, E., Barnes, S., Acuto, M., \& Mcneill, D. (2017). Digital Infrastructures and Urban Governance. Urban Policy and Research, 35, 20-31.

https://doi.org/10.1080/08111146.2016.1235032

David, M., \& Sauviat, C. (2019). Intelligence Artificielle: La Nouvelle Barbarie. Edition du Rocher.

Etzkowitz, H., \& Leydesdorff, L. (1995). The Triple Helix: University-Industry-Government Relations: A Laboratory for Knowledge Based Economic Development.

Eveno, E. (2018). La villeintelligente, objet de nombreuses controverses. Quaderni, 96, 29-41. https://doi.org/10.4000/quaderni.1174

Hajduk, S. (2016). The Concept of a Smart City in Urban Management. Business, Management and Education, 14, 34-49. https://doi.org/10.3846/bme.2016.319

Harrison, C., \& Donnelly, I. A. (2011) A Theory of Smart Cities. In Proceedings of the 55th Annual Meeting of the ISSS-2011, Hull, 17-22 July 2011.

Héraud, J.-A., Kerr, F., \& Burger-Helmchen, T. (2019). Creative Management of Complex Systems. ISTE, Wiley. https://doi.org/10.1002/9781119332466

Kraus, S., Richter, C., Papagiannidis, S., \& Durst, S. (2015). Innovating and Exploiting Entrepreneurial Opportunities in Smart Cities: Evidence from Germany. Creativity and Innovation Management, 24, 601-616. https://doi.org/10.1111/caim.12154

Kuhlmann, S., Boekholt, P., Georghiou, L., Guy, K., Héraud, J-A., Larédo, P., Lemola, T., Loveridge, D., Luukkonen, T., Polt, W., Rip, A., Sanz-Menendez, L., \& Smits, R. (1999). Enhancing Distributed Intelligence in Complex Innovation Systems. Report Published within the Framework of the Targeted Socio-Economic Research Program of the European Commission, ISI-FhG.

Kumar, T. M. V. (2017). Smart Economy in Smart Cities. Springer Nature.

Nalbandian, J., O’Neill, R., Michael Wilkes, J., \& Kaufman, J. (2013). Contemporary Challenges in Local Government: Evolving Roles and Responsibilities, Structures, and Processes. Public Administration Review, 73, 567-574. https://doi.org/10.1111/puar.12059

Nam, T., \& Pardo, T. (2011). Conceptualizing Smart City with Dimensions of Technology, People, and Institutions. In The Proceedings of the 12th Annual International Conference on Digital Government Research (pp. 282-291). https://doi.org/10.1145/2037556.2037602

Porter, M. (1998). Clusters and the New Economics of Competition. Harvard Business Review, 76, 77-90.

Porter, M. (2000). Location, Clusters and Company Strategy. In: G. Clark, M. Gertler, \& M. Feldman (Eds.), Oxford Handbook of Economic Geography (pp. 253-274). Oxford 
University Press.

Richter, C., Kraus, S., \& Syrjä, P. (2015). The Smart City as an Opportunity for Entrepreneurship. International Journal of Entrepreneurial Venturing, 7, 211-226. https://doi.org/10.1504/IJEV.2015.071481

Sen, A. (2009). The Idea of Justice. Allen Lave \& Harvard University Press.

Thaler, R. H., \& Sunstein, C. R. (2008). Nudge: Improving Decisions about Health, Wealth, and Happiness. Yale University Press.

Vidalenc, E. (2019). Pour une ecologie numérique. Les Petits Matins and Institut Veblen.

Waart van, P., Mulder, I., \& de Bont, C. (2016). A Participatory Approach for Envisioning a Smart City. Social Science Computer Review, 34, 708-723.

https://doi.org/10.1177/0894439315611099

Wang, M. (2015). Smart Cities of the Future: Creating Tomorrow's Education toward Effective Skills and Career Development Today. Knowledge Management \& E-Learning, 6, 344-355. https://doi.org/10.34105/j.kmel.2014.06.023 